\title{
Exergoeconomic Distillation Sequencing by Multi-objective Optimization through a Hybrid Genetic Algorithm
}

\author{
Y. Özçelik ${ }^{\mathrm{a}, \mathrm{b}}$ and S. O. Mert ${ }^{\mathrm{a}, *}$ \\ ${ }^{a}$ Yuzuncu Y1l University, Faculty of Engineering and Architecture, \\ Department of Chemical Engineering, Kampüs, Van, 65080, Türkiye \\ ${ }^{b}$ Ege University, Faculty of Engineering, Department of Chemical \\ Engineering, Bornova, İzmir, 35100, Türkiye
}

doi: 10.15255/CABEQ.2015.2202

Original scientific paper

Received: March 13, 2015

Accepted: September 8, 2016

\begin{abstract}
While trying to optimize sharp distillation processes, the number of possible column sequences significantly increases as the number of components that make up the feed mixture increases. As a result, proper sequencing with maximum exergetic profit and minimum exergy destruction becomes harder to achieve. In this study, an exergoeconomic multi-objective optimization was applied to the distillation sequences of three separate hydrocarbon mixture cases, by means of a genetic-algorithm-based solver software. A computer program (DISMO) was developed in-house to achieve this functionality. The results indicate that the created algorithm was quite applicable in determining the optimum sequencing in distillation, as it successfully created the Pareto Solution Set and suggested the optimum configurations. This study also presented an opportunity to conduct a parametric investigation on various weighting factors for objective functions. As the importance given to a specific objective was increased, the optimization results had a tendency to favour that specific objective through arrangement of sequencing as expected, though the profit and sequencing converged to a single result after a certain threshold.
\end{abstract}

Key words:

distillation sequencing, genetic algorithm, exergoeconomy, multi-objective optimization, distillation

\section{Introduction}

"Distillation" is a popular and widely used separation system in chemical processes, which requires extensive amounts of energy input. Handling the separation of hydrocarbon mixtures is also among the main challenges of chemical processes throughout the world. As such, in order to reduce their operational energy levels, distillation systems demand a high emphasis on optimization during their design phase. At the outset, the amount of energy consumption in the system, along with the initial capital investment and design efficiency, are crucial properties to consider.

Another commonly faced issue is the determination of proper sequencing and configuration for the distillation columns. The optimal design of a separation system, including detailed column configuration and the column sequencing, presents a rather complex problem. This complexity arises due to a system's nonlinear, mixed-integer superstructural nature that depends on the number, type, and compositions of components involved.

${ }^{*}$ Corresponding author: Tel.: +90 505 2356022; Fax:+904322251730; E-mail address: orcunmert@gmail.com,orcunmert@yyu.edu.tr (S. O. Mert)
There are various studies in the literature about distillation systems. Some focus purely on energy optimization, while others search for a better sequencing and consider a multi-objective approach. A sample sequencing for a separation system, including a special hierarchical structure, is proposed in the study of Wang et al., and is modelled as a multi-hierarchy combinatorial optimization ${ }^{1}$. An earlier work was conducted where sequencing and heat integration were brought together and optimization was based on minimizing the cost of the columns $^{2}$. In the study of Jain, Smith, and Kim, energy-efficient distillation systems were sought after by optimization of distillation sequencing, in which heat integration was also considered as a primary factor ${ }^{3}$.

Various solutions for this complex superstructure of column-sequencing were also demonstrated in the literature for separation of azeotropic mixtures $^{4,5}$. In one study, a multi-objective approach was used for optimization of a compressor-aided distillation system sequencing ${ }^{6}$. Another study applied exergetic single-objective optimization to a distillation system, and sequencing was considered as a primary factor ${ }^{7}$. The design of distillation columns themselves and related separation systems 
were also handled in various studies on reactive distillation $^{8,9}$ and heat integration systems ${ }^{10}$.

Research in the literature also evaluates various distillation systems, including batch columns, solar driven membrane systems, and multi-effect columns. From an optimization point of view, most of these use meta-heuristic methods, such as simulated annealing and genetic algorithms, based on the low risk of local optima problems, ease of development, and/or lack of commercial availabilities ${ }^{9,11-14}$. In some studies, simulation programs like Aspen and MATLAB are used to evaluate the flowcharts and physical data, in order to decrease the code development time and costs ${ }^{15}$.

Unlike the mentioned studies, this paper approaches the problem by considering a multi-objective optimization of distillation sequencing from exergoeconomic profit and exergy destruction points of view. A computer program was developed to solve this complex problem. It is based on a hybrid genetic algorithm that designs each column in detail, including various properties like the cost, and then attempts to optimize the sequencing for these columns considering user-defined objective functions. Uniquely through in-house software development, combining exergy concept with multi-objective optimization, this study will hopefully be a considerable contribution to the research focused on separation systems, especially for the distillation trains.

\section{Distillation sequencing and design}

Hydrocarbon mixtures are widely handled in the chemical industries due to their broad daily usage, and growing global energy demands. Proper separation of components of such mixtures is accomplished mainly through distillation trains. Accurate evaluation and determination of the best distillation sequence for a multi-component mixture are complex problems, both mathematically and economically.

Selection of the proper sequencing for a sharpsplit distillation of a multi-component mixture presents a mixed-integer nonlinear programming (MINLP) problem $^{16}$. The software developed for this project (DISMO) models the placement of columns, along with detailed column design parameters like reflux ratios, vapour/liquid ratios, and plate design. It also models various variables and formulae to perform necessary cost and profit calculations. The following section describes the model in detail, and shows how these variables and formulae were implemented into DISMO.

The decision on the sequencing of a distillation train strongly affects the design of each column in the system, and eventually has a considerable effect on the investment and operating costs of the process. Moreover, as the separation characteristics of the mixtures fed in the columns of the distillation train change, exergetic efficiency is also altered, depending on the exergy destruction properties of the mixture. Laying on to these phenomena, the exergoeconomic cost of the separation operation also changes.

The number of possible sequences for a sharp distillation increase remarkably with the number of components of the feed mixture, and an exact number of possible solutions can be calculated using the following equation ${ }^{2}$ :

$$
N S=\frac{[2(N C-1)] !}{N C !(N C-1) !}
$$

where NS and NC are the number of possible distillation sequences and number of compounds, respectively. A computer-based optimization algorithm can examine many alternative distillation sequences to determine the best one for a given criterion.

Genetic algorithms have some unusual inner mechanisms, like mutation and crossing over, therefore, it is convenient to represent the data in a format that is more compatible with these properties. With this in mind, each possible sequence for separation of a mixture can be represented by a binary vector with $2 \mathrm{NC}-1$ elements, or with $\mathrm{NC}-1$ elements when using a continuous variable vector ${ }^{17}$. For example, a mixture involving five components - like A, B, C, D, E - can be represented by an array as given in Figure 1, which eases further implementation into genetic algorithm. (Easier to mutate, cross-over and reproduce.) In the figure, a sample array formation is presented, and the separation numbers and end product numbers are shown. With this approach, the result depends on what the determined separation points are, and a sequence "number" is formed according to the developed binary sequencing.

The operating variables for each column, such as reflux ratio, "feed vapour/liquid ratio", and column pressure, are dominant parameters that affect the characteristics of the design. If the feed conditions, pressure, reflux ratio, and the material quality can be determined, the capital investment and operating costs for the columns in the sequences can be calculated with sharp distillation-column design techniques. To determine the cost of a column, it is necessary to calculate the diameter, height, and minimum number of trays in the columns ${ }^{18}$. The diameter $\left(D_{c}\right)$, minimum number of trays $\left(N_{\min }\right)$, and the height of the column $\left(H_{c}\right)$ are calculated as follows: 


$$
\begin{gathered}
D_{\mathrm{c}}=\left\{\frac{4}{\pi} \cdot D_{\mathrm{F}} \cdot(R+1) \cdot \frac{22.2 T_{\mathrm{D}}}{0.761(1 / p)^{0.5} \cdot 273} \cdot \frac{1}{3600 P}\right\}^{0.5} \\
N_{\min }=\frac{\ln \left[\frac{n_{L K, D} n_{H K, B}}{n_{H K, D} n_{L K, B}}\right]}{\ln \propto_{L K-H K}} \\
H_{\mathrm{c}}=0.61 \frac{N}{\eta}+4.27
\end{gathered}
$$

where $R$ is the reflux ration, $p$ is pressure, $T_{\mathrm{D}}$ is the dew point of the mixture, $N$ is the number of trays, and $h$ is the tray efficiency. The condenser and reboiler duty of each column is calculated, and necessary utilities are also evaluated for exergy analysis, using the following equations:

$$
\begin{gathered}
Q_{\mathrm{c}}=(R+1) \cdot D_{\mathrm{F}} \cdot \lambda_{\text {top }} \\
Q_{\mathrm{H}}=H_{\text {bot }}+H_{\text {top }}+Q_{\mathrm{c}}-H_{\text {feed }}
\end{gathered}
$$

where $H$ represents the enthalpies of feed, bottom, and top products, and $Q$ represents the heat duties of condenser and reboiler. $\lambda$ is the latent heat of vaporization.

The costs of the columns depend on these calculated parameters, like the height, diameter, and heat duties. The correlations proposed by Guthrie ${ }^{19}$ are used for the evaluation. (Although the correla-

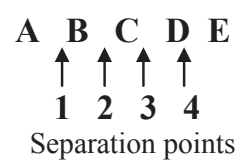

$\mathrm{BV}=4,1,0,0,3,2,0,0,0 \quad(0$ represents end products $)$

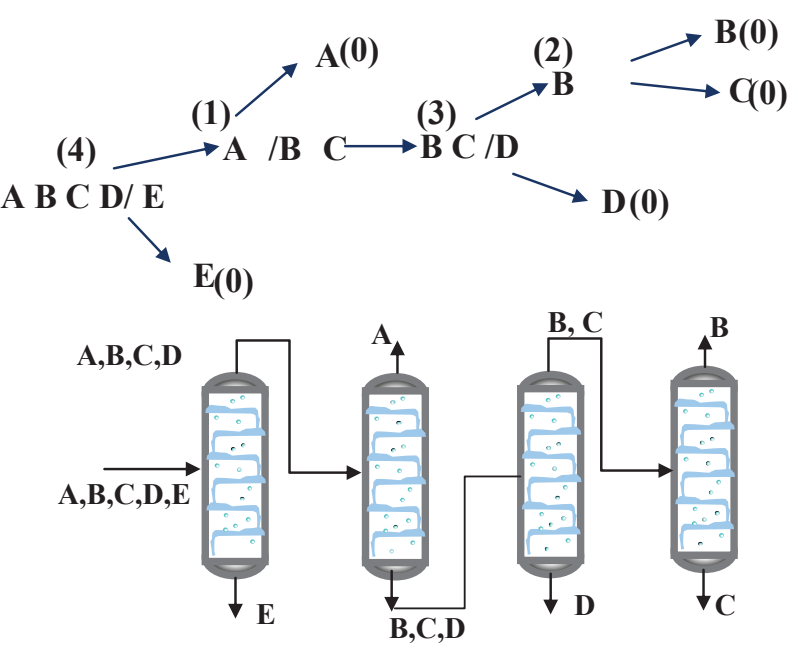

Fig. 1 - Binary variable (BV) representation and visualization of an alternative distillation sequence tion method cannot change either the solution method or the definition of the problem, alternative correlation methods were still included in the computer software for user convenience.) In our software model, general design vessels were defined in accordance with ASME codes, and the equipment thicknesses were calculated to resist $4.5 \mathrm{~atm}$ of internal pressure. Trays, tray assemblies, packed beds, lining, and other internals are also priced and added to the general cost. Column and tray costs are calculated with the formulae below:

$$
\begin{gathered}
C_{\text {column }}=\left(\frac{\mathrm{M} \& \mathrm{~S}}{280}\right) \cdot 101.9 \cdot\left(D_{\mathrm{c}} / 0.3048\right)^{1.066} \\
\cdot\left(H_{\mathrm{c}} / 0.3048\right)^{0.802} \cdot\left(2.18+F_{\mathrm{c}}\right) \\
C_{\text {tray }}=\left(\frac{\mathrm{M} \& \mathrm{~S}}{280}\right) \cdot 4.7 \cdot\left(D_{\mathrm{c}} / 0.3048\right)^{1.55} \cdot(1.64 N T) \cdot F_{\mathrm{c}}(8)
\end{gathered}
$$

where $F_{c}$ is the cost index for columns, $D_{\text {c }}$ is the diameter of the column, and $\mathrm{M} \& \mathrm{~S}$ is the Marshall and Swift Index.

The total column cost in the distillation sequence is calculated using the column, tray, and utility costs, with the following formula:

$$
T C C=\left(C_{\text {Column }}+C_{\text {Tray }}+C_{\text {Cond }}+C_{\text {Reb }}\right) / t_{\mathrm{L}}
$$

where TCC is the total column cost, $t_{\mathrm{L}}$ is the lifetime of the system, and $C$ is the separate costs of systems parts.

Finally, depending on the cost of all columns, the total annual cost of the distillation sequence $(T A C)$ is calculated with the formula:

$$
T A C=\sum_{i=1}^{N C-1} T C C_{i}
$$

\section{Exergoeconomic Multi-objective Optimization (ExMOO)}

Multi-objective optimization is a mathematical programming technique that considers multiple objectives explicitly and simultaneously. Most of the physical and chemical phenomena in distillation system separation processes are multi-objective by nature and have complex superstructures. Fortunately, there are some methods available to tackle these kinds of problems.

In this study, a comprehensive exergoeconomic multi-objective optimization (ExMOO) was applied to predefined hydrocarbon mixtures to find out the optimum sequence for their sharp distillation, and the objectives to optimize were "maximization of exergoeconomic profit" $\left(P_{e x}\right)$ and "minimization of exergy destruction" $\left(E x_{D}\right)$. 
Maximum exergoecenomic profit and minimum energy destruction are calculated with the following formulae:

$$
\begin{aligned}
\operatorname{Max}_{E x}= & \left(E x_{T o p} \cdot C_{T o p}+E x_{B o t} \cdot C_{B o t}\right)- \\
& -\left(E x_{F} \cdot C_{F}+E x_{C U} \cdot C_{C U}+E x_{H U} \cdot C_{H U}+Z\right)
\end{aligned}
$$

Min $E x_{D}=E x_{F}+E x_{C U}+E x_{H U}-E x_{O u t}$

where $E x$ is the exergies of top and bottom products, and $C$ is the cost of the products. $\mathrm{F}$ denotes the feed, whereas $\mathrm{CU}$ and $\mathrm{HU}$ correspond to cooling and heating utility, respectively.

In our model, the "weighted sum of objectives" method was used to deal with the complex superstructure of this multi-objective problem. In this method, a weight factor value between 0 and 1 is given to each of the objective functions, which have to total 1 . With this setup, the decision about the weight factors becomes the crucial factor for the solution. The software developed for this study offers the users an opportunity to determine the weighting factors with a user-friendly interface. On the other hand, it is also capable of automatically running the tests with various weight factor distributions itself, as well as display the results for all of them in a coherent manner. When this happens, the multi-objective problem is solved separately for each case of weight distribution. In this study, three different cases of mixtures, each with different compositions with varying number of components, were inspected for their optimum distillation sequencing, and the software delivered a large Pareto set for the given targets of highest exergoeconomic profit and lowest exergy loss. The results of this study are discussed considering this broad Pareto solution set.

Before going into details, let us see how the model mathematically combines the objectives of maximum exergoeconomic profit and minimum exergy loss:

$\operatorname{Min} Z=\left(w\left(P_{E x}-P_{E x, \max }\right)^{2}+(1-w)\left(E x_{D}-E x_{D, \text { Min }}\right)^{2}\right)^{1 / 2}$

In this formula, $Z$ is the objective function to be minimized by uniting two separate objective functions.

As discussed before, in addition to the optimization capabilities, the ability to perform parametric investigations over the weighting factors was also implemented to DISMO. The program automatically runs the algorithm for many possible weight factor distribution configurations, and gathers the results in user-friendly chart displays. This leads to an opportunity to observe and evaluate the behaviour of the multi-objective optimization model, in which the conflicting natures of "profit" and "energy" are evident. Even having an exergoeconomic structure does not change this fact, and the trade-off between objectives lies on the efficiency - production costs axis. As is the situation with general engineering problems, the aim of efficient "work" for the system, from the energy point of view, leads to other difficulties in the separation process in distillation, and thus, increases the costs.

Exergoeconomic analysis helps fight these economic concerns with exergy analysis, equipment costs, and related thermodynamic irreversibilities through the system. Exergy may be defined as the maximum available work during the period a system first interacts with its surroundings until it comes to equilibrium. From this point of view, it is obvious that exergy deals with the "quality" of the energy, compared to the standard term of "energy", which only deals with its quantity. Nevertheless, exergy and costs are closely related, and exergy analysis seeks the most efficient and effective use of energy throughout a given system. Exergy analysis is thus a potential tool for system design, analysis, and process evaluation. Exergetic analysis of a system helps to identify the primary sources of losses and provide a realistic performance analysis. This approach lays the foundations for cost-effective operation.

The exergetic efficiencies of each column and the sequences considering the exergy destruction is calculated according to the exergy balance ${ }^{20,21}$. The exergy loss is calculated with the following formula:

$$
E x_{\text {dest }}=E x_{\text {in }}-E x_{\text {out }}
$$

where $E x_{i n}$ is the total exergy entering the system, and $E x_{\text {out }}$ is the exergy leaving the system boundaries. These values are calculated using regular exergy calculations ${ }^{22}$, considering the distillation column and component fraction as the system boundaries. When calculating the exergy efficiency, the rate of exergy recovered (exergy output) to the exergy input is taken into account. Exergy output can be defined as the desired exergy output or useful exergy output ${ }^{23}$. Exergy efficiency is calculated with the following formula:

$$
\eta=\frac{E x_{\text {out }}}{E x_{\text {in }}}
$$

Exergoeconomic analysis will also help find the exergetic cost for the separation process. Such cost calculations are generally used to run feasibility studies and evaluate investment decisions, and as a comparison point for alternate techniques. With all these in mind, when attempting to create a sustainable cost-effective operation and determine the operating conditions for it, exergoeconomic analysis should always be considered ${ }^{24,25}$. 
Exergoeconomic analysis aims at the following $^{26,27}$ :

- to identify the location, magnitude, and sources of thermodynamic losses,

- to calculate the cost associated with exergetic losses and destroyed exergy in any system component,

- to analyse the cost formation of each subsystem and product separately.

The overall exergetic cost balance is calculated with the formula:

$\sum\left(\dot{E x}_{\text {in }, i} \cdot C_{\text {in }, i}\right)+\dot{Z}_{\text {tot }}=\sum\left(\dot{E}_{\text {out }, i} \cdot C_{\text {out }, i}\right)+P_{\text {net }} \cdot C_{W}$

where $\dot{E} x_{i n, i}, \dot{E} x_{\text {out }, i}, C_{\text {in } i}$ and $C_{\text {out } i}$ are the exergies and exergy costs of the inlet and outlet streams, $\dot{Z}_{\text {tot }}$ is the annualized cost of the total system inside the control volume, $\mathrm{C}_{W}$ is the cost of the work or the power of the equipment, and $P_{\text {net }}$ is the net power produced from the separation system.

The cost balance is applied to the whole system in order to calculate the cost of the separation system, and depending on these, the exergetic profit is calculated. In order to calculate $Z_{\text {equipment }}$ the annualized (or levelized) cost method is used ${ }^{28}$.

All of the constraints in the problem are in the form of equalities, and these equalities are given in the model. The only unknown variables within the problem are the configuration of the distillation columns and reflux ratios for each solution. The binary variables - in vector form - to determine the configuration are restricted by 0 and 1 , and can have no other value. The continuous variables to determine the reflux ratio of the distillation columns are constrained between 0.5 and 4 .

\section{DISMO computer program}

This study covers the production of a Multi-objective Optimizer (MOO) program based on hybrid genetic-algorithm solver (DISMO) implementation, (Figure 2) in order to solve the complex nature of distillation of mixtures.

DISMO runs a subprogram (CRANE), which was also developed by our group. CRANE governs a database of 650 components ready for evaluation, with all their physical and thermodynamic properties defined, including a detailed steam table for each of them. Each of these components is ready to be implemented in a case study.

The feed's thermal properties (i.e. temperature) and compositions entered by the user are dynamically read by DISMO, and the related thermodynamic and physical data for the mixture are automatically calculated by proper subroutines.

In the study, minimization of the function formed by multiple-objectives that are combined by weighted sum of objectives method, is achieved ${ }^{29}$ by use of a "Nonlinear Simplex/Genetic" hybrid algorithm, which is based on the stochastic generation of solution vectors.

The algorithm of the DISMO is given in Figure 3. The calculations start after the data entry, which is followed by estimation of the physical and thermodynamic properties of components, after which the genetic algorithm is initialized. Evaluation of the objective function is dependent on the weighting factor and fitness function produced by the genetic algorithm. The program simultaneously attempts to optimize both minimization of the exergy destruction and maximization of the exergetic profit.

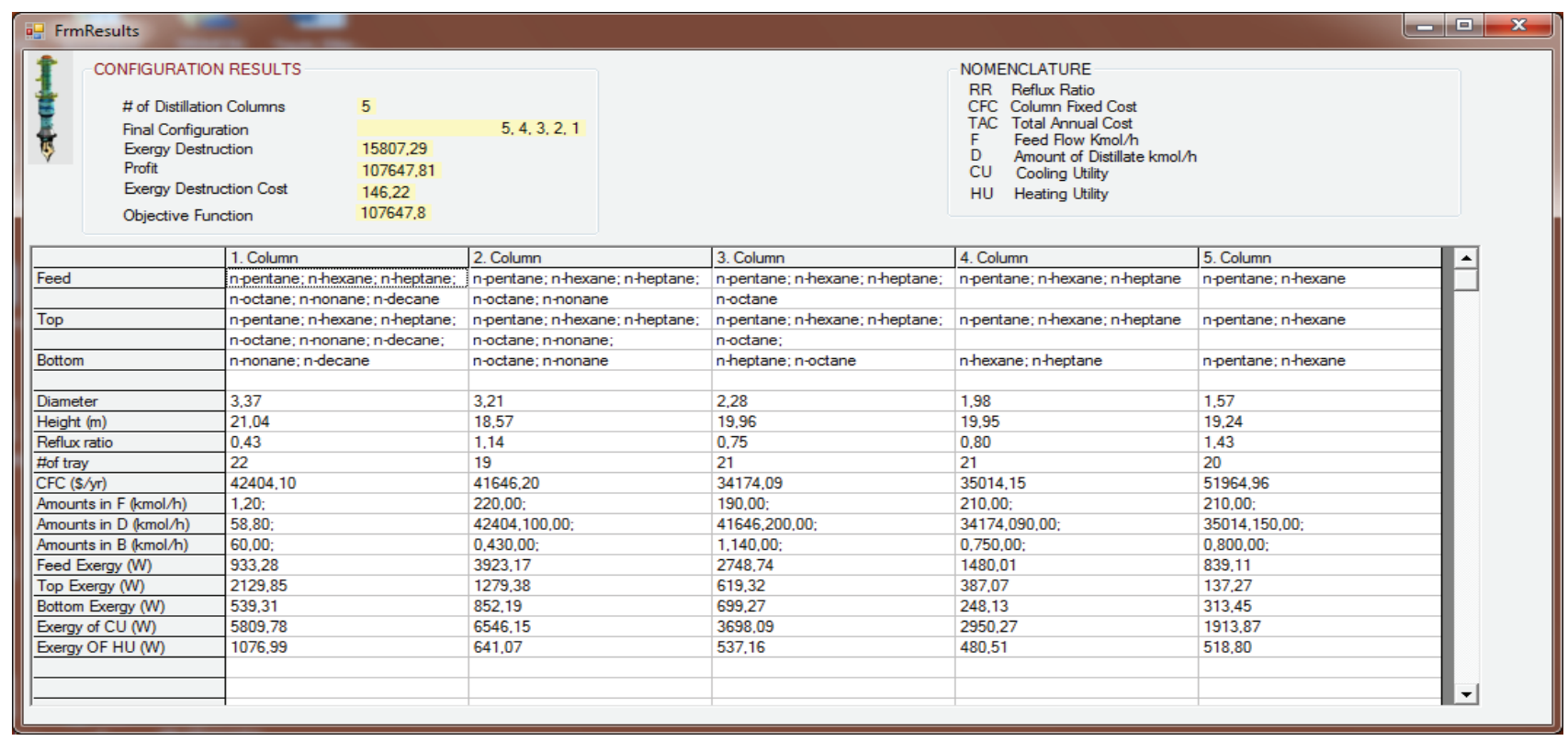

Fig. 2 - Sample results screen of the DISMO computer program 


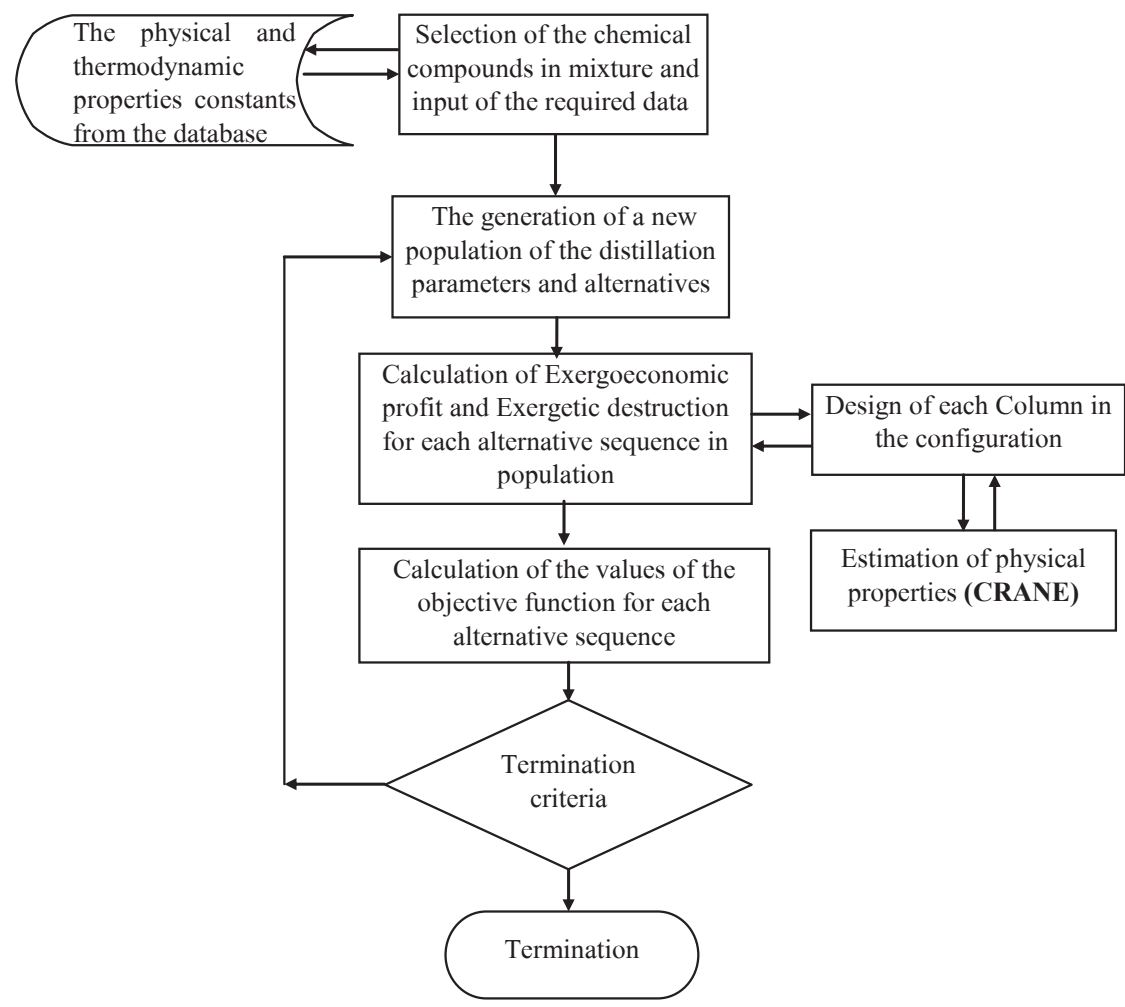

Fig. 3 - DISMO computer program algorithm

Termination criteria change depending on the structure of the solution. In a small number of possible solutions, the program ends when it calculates every alternate and offers a set of solutions from among them. In case of a large number of alternatives, on the other hand, the genetic algorithm is strictly applied and the program ends when convergence of the fitness function is reached.

The basic steps of the genetic-algorithm are as follows:

- Encoding and generation of the initial population, depending on the number of variables.

- The generation of a new population

- Reproduction

- Crossover

- Mutation

- Generation of new random vectors

- Termination criteria

$$
\operatorname{abs}\left(F_{\operatorname{Avg}_{i}}-F_{\operatorname{Avg}_{i-25}}\right) \leq \epsilon
$$

$F_{A v g_{i}}$ and $F_{A v g_{i-25}}$ are the average objective function values for 25 consecutive generations, and this formula is the termination control criteria that controls the convergence of the algorithm.

The performance of the developed genetic algorithm was tested with 50 different seeds, using pseudo-random numbers given on MINLP engi-
Table 1 - Parameters for genetic algorithm

\begin{tabular}{l|c}
\hline \multicolumn{1}{c|}{ Parameter } & Value \\
\hline Reproduction ratio & 0.3 \\
Crossover ratio & 0.4 \\
Mutation ratio & 0.05 \\
Generation ratio of new random vectors & 0.25 \\
\hline
\end{tabular}

neering test problems ${ }^{30}$, in order to determine the values for the critical parameters for these types of problems. These critical parameters are: population size, reproduction ratio, crossover ratio, mutation ratio, generation ratio of new random vectors, and termination criteria. The optimum values found in this study for the population size, reproduction ratio, crossover ratio, mutation ratio, and generation ratio of new random vectors are given in Table 1.

Population size was taken as $10 \mathrm{xN}(\mathrm{N}$ is the number of unknown variables, and depends on the problem)

\section{Case studies}

Three hydrocarbon mixtures were selected as case studies to be investigated by the program on a complex separation system, to reveal its performance. Since each mixture had a different number 
Table 2 -Feed compositions and properties of cases

\begin{tabular}{l|c|c|c}
\hline \multicolumn{1}{c|}{ Component/Property } & Case 1 & Case 2 & Case 3 \\
\hline n-Pentane [mol \%] & - & 20 & 20 \\
n-Hexane [mol \%] & 30 & 20 & 20 \\
n-Heptane [mol \%] & - & 20 & 10 \\
n-Octane [mol \%] & 28 & 20 & 20 \\
n-Decane [mol \%] & 42 & 20 & 10 \\
n-Nonane [mol \%] & - & - & 20 \\
Pressure [atm] & 1 & 1 & 1 \\
Temperature [ $\left.{ }^{\circ} \mathrm{C}\right]$ & 40 & 40 & 40 \\
Flow rate $\left[\mathrm{kmol} \mathrm{h}^{-1}\right.$ ] & 600 & 600 & 600 \\
\hline
\end{tabular}

of components, each case had different unknown variables. Meanwhile, accuracy of the termination criteria was tested by increasing the number of evaluations in later cases. It was observed that the original form of the termination criteria was suitable, even when the number of unknown variables was increased.

Table 2 shows molar compositions of the mixtures for each case, as well as the temperature, pressure, and flow rate of feed to the first column of the system.

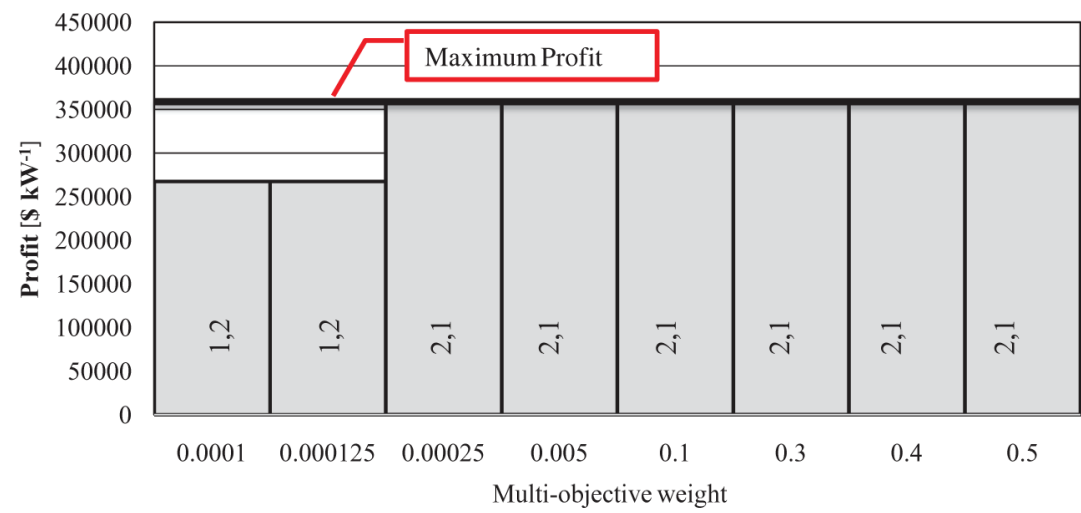

Fig. 4 - Variation of exergoeconomic profit depending on the weighting factor for Case 1

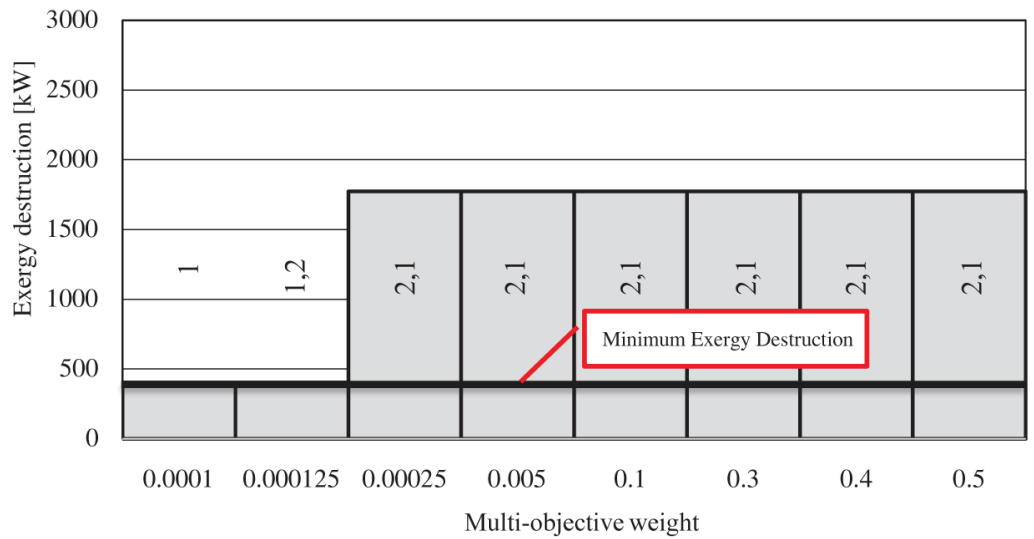

Fig. 5 -Variation of exergy destruction depending on the weighting factor for Case 1
Table 3 -Design results of Case 1

\begin{tabular}{c|c|c|c|c|c|c|c|c}
\hline \multirow{2}{*}{ Column } & \multicolumn{3}{|c|}{ Maximum Profit } & \multicolumn{4}{c}{$\begin{array}{c}\text { Minimum Exergy } \\
\text { Destruction }\end{array}$} \\
\cline { 2 - 10 } & \multicolumn{3}{|c|}{$358708.3\left[\$ \mathrm{~kW}^{-1}\right]$} & \multicolumn{4}{c}{$403.84[\mathrm{~kW}]$} \\
\cline { 2 - 9 } & $D_{\mathrm{c}}$ & $H$ & $N_{\mathrm{T}}$ & $R$ & $D_{\mathrm{c}}$ & $H$ & $N_{\mathrm{T}}$ & $R$ \\
{$[\mathrm{~m}]$} & {$[\mathrm{m}]$} & {$[-]$} & {$[-]$} & {$[\mathrm{m}]$} & {$[\mathrm{m}]$} & {$[-]$} & {$[-]$} \\
\hline 1 & 2.41 & 23.72 & 26 & 0.15 & 1.70 & 15.52 & 15 & 0.24 \\
2 & 1.74 & 50 & 60 & 0.58 & 1.93 & 18.70 & 19 & 0.77 \\
\hline
\end{tabular}

In addition to all of these, the each of the cases was investigated separately for a range of weighting factors. These were selected depending on the behaviours of the distillation systems. Each case is slightly different in the range of weighting factors, based on the convergence of one of the objective functions to its maximum value, which is found by single optimization. (Giving either objective the maximum possible weight factor of 1 )

\section{Results and discussion}

Each case of the parametric investigation had a different trend, depending on the details of each column's design, and exergetic costs. As the multi-objective weight of one objective function tended toward 0 , the optimization converged to a single criteria optimization from the other objective's point of view.

The exergoeconomic profit for Case 1 is represented in Figure 4, which compares the variation of the weighting factors for the profit objective. Considering that the mixture fed in Case 1 had 3 components, it required 2 distillation columns for separation, and thus, there were only 2 alternatives for the separation sequencing of this mixture. As can be seen from the figure, increasing the weight factor of the profit objective put the system on a final configuration of 2-1 at some point. Any further increase did not change the result, as there was no alternative sequencing. Figure 5 shows the investigation in the other perspective. Here, as the weight factor for the profit increases, the exergetic destruction also increases, and proves the conflicting situation between the objectives. The numerical results for the details of the columns of the separation system are given in Table 3 . The maximum prof- 
it reaches up to $358707.5 \$ \mathrm{~kW}^{-1}$, while minimum exergy destruction is 403.84 $\mathrm{kW}$.

The situation was quite different for Case 2, when the number of components forming the mixture increased. Figure 6 shows how the variation of the exergoeconomic profit increases by up to 30 $\%$ with respect to its given weight. The maximum value for profit reaches up to $116826 \$ \mathrm{~kW}^{-1}$ with a sequencing of 4-3$2-1$. It shows that there are only 4 sequencing schemes with better cost and efficiency values. It also shows the difference in the objective function with the variation of the reflux.

Since mixture properties and compositions are varied, each column has a different structure depending on the sequence selected. This complex structure is evaluated from an exergy destruction point of view in Figure 7. It is evident that the first sequences of 2-3-4-1 have better exergy destruction results compared to better profit sequences, such as the previously mentioned 4-3-2-1. The minimum destruction that can be reached is $5132.42 \mathrm{~kW}$, and is approximately $10 \%$ higher than the global minimum.

The interdependence of overall profit and exergy destruction, based on the selection of the column configuration and sequence, can clearly be seen (Figure 8) in Case 3, which has a 6-component mixture in the feed. There are small numerical variations in profit and exergy destruction for the same sequence. These similarities and small differences arise from the small impacts of the reflux ratio and other configuration parameters. The main component for profit and exergy destruction is still the decision of sequencing, in which all the parameters change, from the mixture properties to the column specifications.

The parametric investigation lets the system converge the maximum profit (Figure 9) 107647.81 $\$ \mathrm{~kW}^{-1}$ with a sequencing of 5-4-3-2-1. The column properties have normal tendencies when taken in for a single perspective. The reflux ratios are in the range of $0.4-4.27$, whereas the heights of the columns reach a maximum of $27 \mathrm{~m}$. On the other hand, minimum exergy destruction cannot exactly be reached in the investigation, but minimum exergy destruction of $9310 \mathrm{~kW}$ is sustained. Increasing the importance given to the profit directly affects the exergy destruction values.

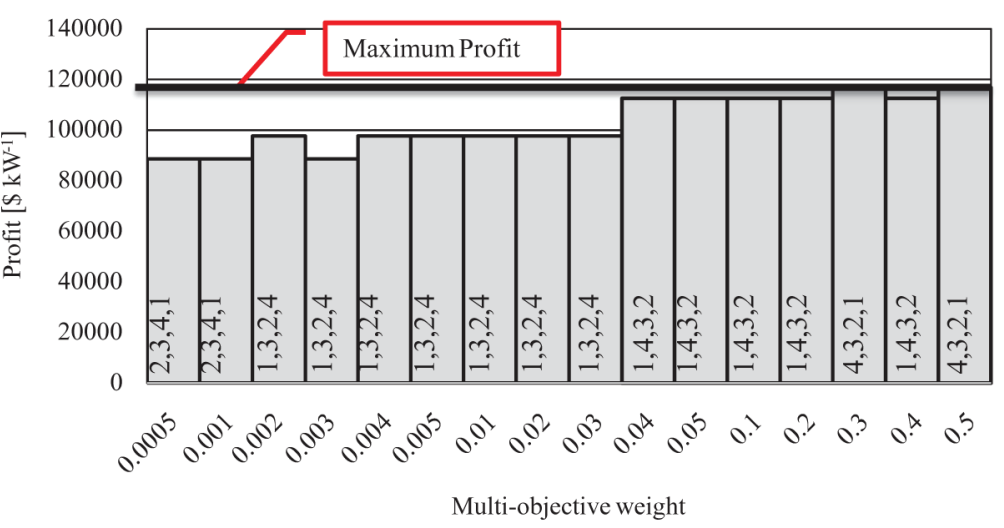

Fig. 6 -Variation of exergoeconomic profit depending on the weighting factor for Case 2

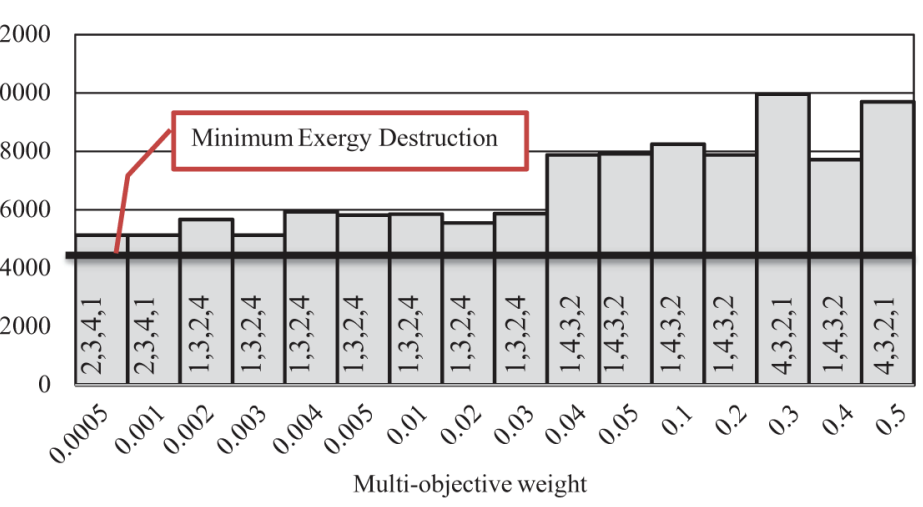

Fig. 7 - Variation of exergy destruction depending on the weighting factor for Case 2

Table 4 -Design results of Case 2

\begin{tabular}{c|c|c|c|c|c|c|c|c}
\hline & \multicolumn{3}{|c|}{ Maximum Profit } & \multicolumn{4}{c}{$\begin{array}{c}\text { Minimum Exergy } \\
\text { Destruction }\end{array}$} \\
\multirow{2}{*}{ Column n } & \multicolumn{3}{|c|}{$116826.9\left[\$ \mathrm{~kW}^{-1}\right]$} & \multicolumn{5}{c}{$4704.1[\mathrm{~kW}]$} \\
\cline { 2 - 10 } & $\begin{array}{c}D_{\mathrm{c}} \\
{[\mathrm{m}]}\end{array}$ & $\begin{array}{c}H \\
{[\mathrm{~m}]}\end{array}$ & $\begin{array}{c}N_{\mathrm{T}} \\
{[-]}\end{array}$ & $R$ & $D_{\mathrm{c}}$ & $H$ & $N_{\mathrm{T}}$ & $R$ \\
& 2.70 & 20.28 & 21 & 0.08 & 1.85 & 13.96 & 13 & 1.43 \\
\hline 1 & 2.77 & 19.43 & 20 & 0.96 & 1.81 & 20.07 & 21 & 1.58 \\
2 & 2.14 & 18.64 & 19 & 1.03 & 1.88 & 29.55 & 33 & 1.76 \\
3 & 1.66 & 16.32 & 16 & 1.67 & 1.53 & 16.63 & 16 & 0.78 \\
\hline 4
\end{tabular}

\section{Conclusion}

In this study, a comprehensive model was developed and multi-objective optimization was implemented to determine the proper distillation sequences for three hydrocarbon mixtures from an exergoeconomic perspective. To achieve this goal, a hybrid, genetic-algorithm-based solver program called "DISMO" was developed. DISMO also has a 


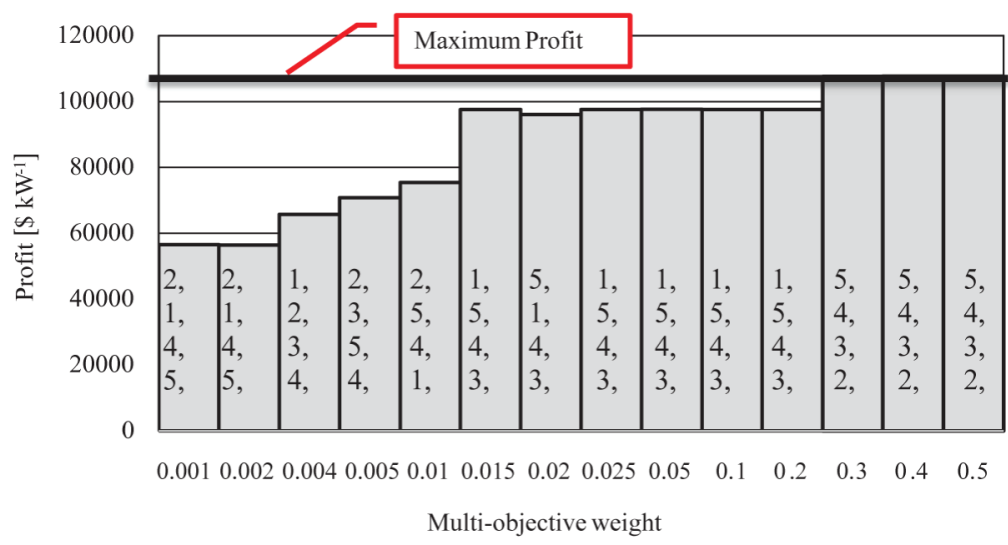

Fig. 8 - Variation of exergoeconomic profit depending on weighting factor for Case 3

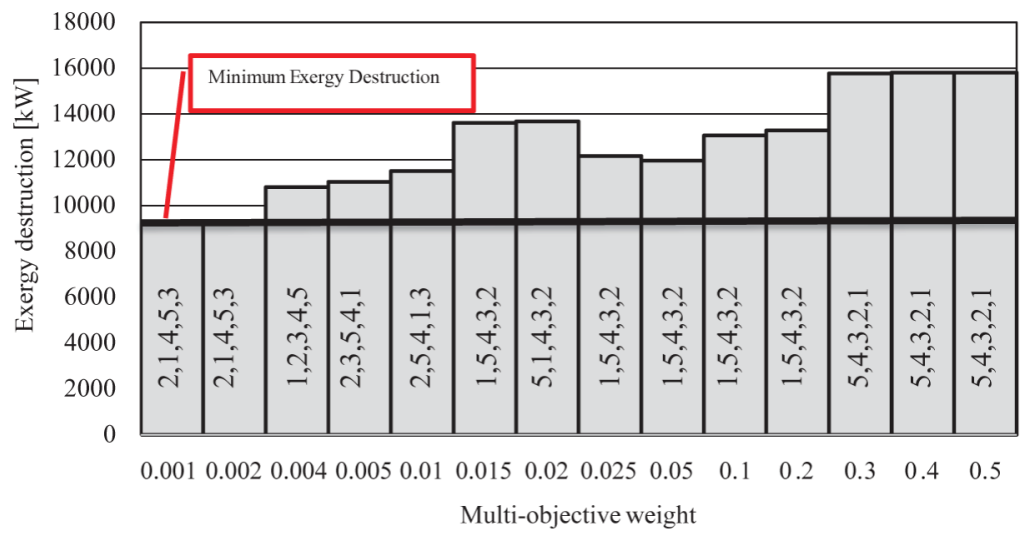

Fig. 9 - Variation of exergoeconomic profit depending on the weighting factor for Case 3

Table 5-Design results of Case 3

\begin{tabular}{c|c|c|c|c|c|c|c|c}
\hline & \multicolumn{3}{|c|}{ Maximum Profit } & \multicolumn{4}{c}{$\begin{array}{c}\text { Minimum Exergy } \\
\text { Destruction }\end{array}$} \\
& \multicolumn{3}{|c|}{$107647.81\left[\$ \mathrm{~kW}^{-1}\right]$} & \multicolumn{4}{c}{$9302.9[\mathrm{~kW}]$} \\
\hline \multirow{2}{*}{ Column } & $D_{\mathrm{c}}$ & $H$ & $N_{\mathrm{T}}$ & $R$ & $D_{\mathrm{c}}$ & $H$ & $N_{\mathrm{T}}$ & $R$ \\
& {$[\mathrm{~m}]$} & {$[\mathrm{m}]$} & {$[-]$} & {$[-]$} & {$[\mathrm{m}]$} & {$[\mathrm{m}]$} & {$[-]$} & {$[-]$} \\
\hline 1 & 3.37 & 21.04 & 22 & 0.43 & 1.88 & 13.57 & 12 & 1.52 \\
2 & 3.21 & 18.57 & 19 & 1.14 & 1.91 & 15.90 & 15 & 1.91 \\
3 & 2.28 & 19.96 & 21 & 0.75 & 2.22 & 26.91 & 30 & 1.44 \\
4 & 1.98 & 19.95 & 21 & 0.80 & 1.82 & 18.98 & 19 & 4.27 \\
5 & 1.57 & 19.24 & 20 & 1.43 & 1.95 & 34.13 & 39 & 1.74 \\
\hline
\end{tabular}

wide chemical database called CRANE, capable of calculating thermophysical properties of materials.

Distillation sequencing, being an energy - and cost-intensive process, is a crucial step in chemical process modelling and optimization. In order to reveal the true characteristics of this complex structure, considering the undeniable performance of exergy analysis on thermal systems, the exergoeconomic perspective was implemented. Using the multi-objective optimization, with the objectives of profit maximization and exergy destruction minimization, our software enabled us to find the best operating conditions for the system in each case. In light of this, the decision-makers' choices can fearlessly shift from best profit to best exergy destruction, as the weighted sum of the objectives method eases the investigation. Furthermore, the genetic algorithm can deliver many other in-between sequence configurations, all viable, and in optimal range. These alternative configurations can make significant contributions to decision-making and ease the heuristic selection.

As a secondary result of the study, a broad PARETO solution set has been gathered for each weighting factor of each case. Every solution in this set is an optimum one, and all can be considered "correct", as all were selected depending on the fitness function of a family of evaluated results in the genetic algorithm. The decision-makers choose what selection is the "best" optimum for their specific needs and circumstances. This study also reveals the tendencies of the system and underlines the system dynamics.

The results revealed that for the 6-component Case 3 mixture, the best values were $107647.810 \$ \mathrm{~kW}^{-1}$ for exergoeconomic profit and $9302 \mathrm{~kW}$ for exergy loss, with sequencings of 5-4-3-2-1 and 2-1-4-5-3, respectively. For Case 2, the best profit was 116826.3 $\$ \mathrm{~kW}^{-1}$ and exergy destruction was $4704.1 \mathrm{~kW}$ in sequencings of 4-3-2-1 and 1-2-3-4, respectively. The results for Case 1 showed that when there were only 3 components and 2 distillation columns (because of the low number of alternatives, the model delivers similarly structured results), the maximum profit converged to $358708.3 \$ \mathrm{~kW}^{-1}$ with $403.84 \mathrm{~kW}$ exergy destruction in a $2-1$ sequence. The small changes in the optimum values were generally the result of reflux ratio and other parameters that affect the model.

This study has also displayed that the major changes in the objective function values were the result of changes in the distillation configuration.

\section{Nomenclature}

C - Column

$C_{\text {column }}$ - Installed capital cost for a distillation column, \$

$C_{\text {Cond }} \quad-$ Capital cost for a condenser, $\$$ 
$C_{c w} \quad-$ Annual cost of cooling medium

$C_{F} \quad-$ Cost of feed, $\$ \mathrm{kmol}^{-1}$

$C_{\mathrm{p}, \mathrm{W}} \quad-$ Heat capacity of water, $\mathrm{kJ} \mathrm{kg}^{-1}{ }^{\circ} \mathrm{C}^{-1}$

$C_{\mathrm{Reb}} \quad-$ Capital cost for a reboiler, $\$$

$C_{\text {tray }} \quad-$ Installed capital cost for trays, $\$$

$C_{T \text { op }} \quad-$ Cost of top product, $\$ \mathrm{kmol}^{-1}$

$C_{\text {Bot }} \quad-$ Cost of bottom product, $\$ \mathrm{kmol}^{-1}$

$C_{\mathrm{i}} \quad-$ Cost of system equipment, $\$$

$C_{\text {in, }} \quad-$ Cost of inlet stream, $\$ \mathrm{kmol}^{-1}$

$C_{\mathrm{CU}} \quad-$ Cost of cooling utility, $\$$

$C_{\mathrm{HU}} \quad-$ Cost of heating utility, $\$$

$C_{\text {out,I }} \quad-$ Cost of outlet stream, $\$ \mathrm{kmol}^{-1}$

$\mathrm{c}_{\mathrm{w}} \quad-$ Unit cost of coolant, $\$ \mathrm{~kg}^{-1}$

$D_{\mathrm{c}} \quad-$ Column diameter, $\mathrm{m}$

$D_{\mathrm{F}} \quad-$ Flow rate of distillate

$E x_{\mathrm{CU}} \quad-$ Exergy of cooling utility, $\mathrm{kW}$

$E x_{\mathrm{D}} \quad-$ Exergy destruction, $\mathrm{kW}$

$E x_{\mathrm{F}} \quad-$ Exergy of feed, $\mathrm{kW}$

$E x_{\text {Top }} \quad-$ Exergy of top product, $\mathrm{kW}$

$E x_{\mathrm{HU}} \quad-$ Exergy of heating utility, kW

$\dot{E} x_{\text {out }, i} \quad$ - Exergy of outlet stream, $\mathrm{kW}$

$\dot{E} x_{i n, i} \quad-$ Exergy of inlet stream, $\mathrm{kW}$

$F_{\mathrm{c}} \quad-$ Cost index for columns, -

$H_{\text {bottom }} \quad-$ Enthalpy of bottoms, $\mathrm{kJ} \mathrm{kmol}^{-1}$

$H_{\mathrm{c}} \quad-$ Height of distillation column, $\mathrm{m}$

$H_{\text {feed }} \quad-$ Enthalpy of feed, $\mathrm{kJ} \mathrm{kmol}^{-1}$

$H_{\text {top }} \quad-$ Enthalpy of distillate, $\mathrm{kJ} \mathrm{kmol}^{-1}$

$M \& S \quad-$ Marshall and Swift index

$n \quad-$ Number of unknown variables

$N_{\text {f }} \quad-$ Molar flow rate

$N \quad-$ Tray number

NC - Number of components

$N_{\text {min }} \quad-$ Minimum number of trays

NS - Number of distillation sequence

$P \quad-$ Exergoeconomic profit, $\$ \mathrm{~kW}^{-1}$

$p \quad-$ Pressure, bar or atm

$P_{\text {net }} \quad-$ Net profit, $\$ \mathrm{~kW}^{-1}$

$Q_{\text {C }} \quad-$ Rate of heat flow for condenser

$Q_{\mathrm{H}} \quad-$ Rate of heat flow for reboiler, $\mathrm{kJ} \mathrm{h}^{-1}$

$R \quad-$ Reflux ratio

$\mathrm{t}_{\mathrm{L}} \quad-$ Lifetime, years

TAC - Total annual cost of a distillation sequence

TCC - Total annual cost of a distillation sequence

$T_{\text {D }} \quad-$ Distillate temperature

$Z \quad-$ Objective function

$\dot{Z}_{\text {tot }} \quad-$ Total annualized cost of equipment, $\$ \mathrm{~s}^{-1}$

$Z_{\text {equipment }}-$ Total annualized cost of equipment, $\$ \mathrm{~s}^{-1}$

$W \quad-$ Multi-objective weight of an objective, -

\section{Subscript}

B - Bottom product

D - Distillate

Dest - destruction

HK - Heavy Key

in - inlet

LK - Light Key

out - outlet

\section{Greek}

A $\quad-$ Relative volatility

$\in \quad-$ Error

$\eta \quad-$ Efficiency

$\eta_{t} \quad-$ Tray efficiency

$\lambda_{\text {top }}-$ Latent heat of vaporization of top components, $\mathrm{kJ} \mathrm{kg}^{-1}$

\section{References}

1. Wang, X.-H., Li, Y.-G., Hu, Y.-D., Wang, Y.-L., Synthesis of heat-integrated complex distillation systems via Genetic Programming, Comput. Chem. Eng. 32 (2008) 1908. doi: 10.1016/j.compchemeng.2007.10.009

2. Wang, K., Qian, Y., Yuan, Y., Yao, P., Synthesis and optimization of heat integrated distillation systems using an improved genetic algorithm, Comput. Chem. Eng. 23 (1998) 125. doi: 10.1016/S0098-1354(98)00254-3.

3. Jain, S., Smith, R., Kim, J. K., Synthesis of heat-integrated distillation sequence systems, J. Taiwan Inst. Chem. Eng. 43 (2012) 525. doi: 10.1016/j.jtice.2012.01.012.

4. Caballero, J. A, Grossmann, I. E., Design of distillation sequences: From conventional to fully thermally coupled distillation systems, Comput. Chem. Eng. 28 (2004) 2307. doi: 10.1016/j.compchemeng.2004.04.010.

5. Bauer, M. H., Stichlmair, J., Design and economic optimization of azeotropic distillation processes using mixed-integer nonlinear programming, Comput. Chem. Eng. 22 (1998) 1271.

doi: 10.1016/S0098-1354(98)00011-8.

6. Alcántara-Avila, J. R., Kano, M., Hasebe, S., Multiobjective optimization for synthesizing compressor-aided distillation sequences with heat integration, Ind. Eng. Chem. Res. 51 (2012) 5911. doi: 10.1021/ie2017527.

7. Özçelik, Y., Exergetic optimization of shell and tube heat exchangers using a genetic based algorithm, Appl. Therm. Eng. 27 (2007) 1849. doi: 10.1016/j.applthermaleng.2007.01.007.

8. Amte, V., Nistala, S. H., Mahajani, S. M., Malik, R. K., Optimization based conceptual design of reactive distillation for selectivity engineering, Comput. Chem. Eng. 48 (2013) 209.

doi: 10.1016/j.compchemeng.2012.09.018.

9. Burri, J. F., Manousiouthakis, V. I., Global optimization of reactive distillation networks using IDEAS, Computers and Chemical Engineering 28 (2004) 2509.

doi: 10.1016/j.compchemeng.2004.06.014. 
10. Gadalla, M., Jobson, M., Smith, R., Optimization of existing heat-integrated refinery distillation systems, Chem. Eng. Res. Des. IChemE 81 (2003) 147. doi: $10.1205 / 026387603321158302$.

11. Hanke, M., Li, P., Simulated annealing for the optimization of batch distillation processes, Comput. Chem. Eng. 24 (2000) 1 . doi: 10.1016/S0098-1354(00)00317-3

12. Chang, H., Wang, G. B., Chen, Y. H., Li, C. C., Chang, C. $L$., Modeling and optimization of a solar driven membrane distillation desalination system, Renew. Energy 35 (2010) 2714. doi: 10.1016/j.renene.2010.04.020.

13. Sayyaadi, H., Saffari, A., Thermoeconomic optimization of multi effect distillation desalination systems, Appl. Energy 87 (2010) 1122. doi: 10.1016/j.apenergy.2009.05.023.

14. Cardoso, M. F., Salcedo, R. L., De Azevedo, S. F., Barbosa, $D$., Optimization of reactive distillation processes with simulated annealing, Chem. Eng. Sci. 55 (2000) 5059. doi: 10.1016/S0009-2509(00)00119-6.

15. More, R. K., Bulasara, V. K., Uppaluri, R., Banjara, V. R., Optimization of crude distillation system using aspen plus: Effect of binary feed selection on grass-root design, Chem. Eng. Res. Des. 88 (2010) 121. doi: 10.1016/j.cherd.2009.08.004.

16. Andrecovich, M. J., Westerberg, A. W., An MILP formulation for heat-integrated distillation sequence synthesis, AIChE J. 31 (1985) 1461. doi: 10.1002/aic.690310908.

17. Özçelik, Y., Exergetic optimization of distillation sequences using a genetic based algorithm, J. Therm. Sci. Technol. 31 (2011) 19

18. Pibouleau, L., Said, A., Domenech, S., Synthesis of optimal and near-optimal distillation sequences by a bounding strategy, Chem. Eng. J. 27 (1983) 9. doi: 10.1016/0300-9467(83)80041-0.
19. Guthrie, K. M., Capital cost estimating, Chem. Eng. Sci. 24 (1969) 114.

20. Mert, S. O., Dincer, I., Ozcelik, Z., Exergoeconomic analysis of a vehicular PEM fuel cell system, J. Power Sources 165 (2007) 244

21. Dincer, I., Rosen, M. A., Exergy: energy, environment and sustainable development, Applied Energy 64 (2012).

22. Dincer, I., Rosen, M. A., Exergy (2007).

23. Mert, S. O., Dincer, I., Ozcelik, Z., Performance investigation of a transportation PEM fuel cell system, Int. J. Hydrogen Energy 37 (2012) 623.

24. Modesto, M., Nebra, S. A., Exergoeconomic analysis of the power generation system using blast furnace and coke oven gas in a Brazilian steel mill, Appl. Therm. Eng. 29 (2009) 2127.

25. Mert, S. O., Özçelik, Z., Dincer, I., Exergoeconomic based multi-objective optimisation of a solid oxide fuel cell system, Int. J. Exergy 14 (2014) 413.

26. Tsatsaronis, G., Winhold, M., Exergoeconomic analysis and evaluation of energy-conversion plants-II. Analysis of a coal-fired steam power plant, Energy 10 (1985) 81.

27. Mert, S. O., Özçelik, Z., Multi-objective optimization of a direct methanol fuel cell system using a genetic-based algorithm, Int. J. Energy Res. 37 (2013) 1256. doi: 10.1002/er.2963.

28. Tsatsaronis, G., Moran, M. J., Exergy-aided cost minimization, Energy Convers. Manag. 38 (1997) 1535.

29. Mert, S. O., Ozcelik, Z., Dincer, I., Comparative assessment and optimization of fuel cells, Int. J. Hydrogen Energy (2014). doi:10.1016/j.ijhydene.2014.11.050

30. Özçelik, Y., Özçelik, Z., Solving mixed integer nonlinear chemical engineering problems via simulated annealing approach, Chem. Biochem. Eng. Q. 18 (2004) 249. 